\title{
MONITORING TECHNIQUES REVEAL DIFFERENCES IN THE SCALE PARASITOID COMPLEX ON PIPFRUIT
}

\author{
P.W. SHAW and D.R. WALLIS \\ The Horticulture and Food Research Institute of New Zealand, P.O. Box 220, \\ Motueka, New Zealand \\ Corresponding author: pshaw@hortresearch.co.nz.
}

\begin{abstract}
A simple procedure to record parasitoids of armoured scale insects (Diaspididae) is described and illustrated using San Jose scale (SJS, Diaspidiotus perniciosus) on apple wood. Pieces of 2-3 year old SJS infested wood were collected during crawler release periods and kept in moistened Oasis ${ }^{\mathrm{TM}}$ floral foam to prevent desiccation. Neonate crawlers were confined to the twigs for up to 2 weeks in ventilated $30 \mathrm{~cm}$ high plastic containers to obtain large numbers of newly settled scale insects. The twigs, still in Oasis, were secured to branches in the same trees from which they had been collected to allow natural parasitism over 2-3 weeks. Twigs were retrieved and returned to the containers for a further 6 weeks. A yellow sticky strip was placed inside the containers to catch emerging parasitoids. The most common parasitoid species caught in a SJS pheromone trap was Encarsia perniciosi, with very low numbers of E. citrina, Aphytis mytilaspidis and Aphytis sp. (? diaspidis). Higher numbers of Encarsia citrina and Aphytis sp. (? diaspidis) were recorded from SJS infested wood. The results indicate that pheromone traps alone do not provide an accurate assessment of the armoured scale insect parasitoid complex on pipfruit.
\end{abstract}

\section{ISOLATION OF CLOVER ROOT WEEVIL (SITONA LEPIDUS) AGGREGATION PHEROMONE}

\author{
J.R. PROFFITT, M.R. McNEILL and S.L. GOLDSON \\ AgResearch, PO Box 60, Lincoln 8152, Canterbury, New Zealand \\ Corresponding author: john.proffitt@agresearch.co.nz
}

Sitona lepidus arrived in New Zealand in the 1990s and the ensuing losses in white clover production made isolation and characterisation of its aggregation pheromone a priority. The presence of a pheromone had been demonstrated by laboratory choice tests, where $70-80 \%$ of adults chose a white clover plant that had been exposed to other adults. Also, S. lepidus females showed positive electrophysiological responses to Sitona lineatus and Sitophilus spp. aggregation pheromones (4-methyl-3,5-heptanedione and 3-hydroxy4-methyl-5-oxoheptane respectively). In field trials during 1999-00, these pheromones attracted 2-3 times as many adult $S$. lepidus as the controls. By contrast, results from the 2000-01 season were inconclusive, probably due to much lower $S$. lepidus adult densities in the trial area. A seasonal effect whereby weevils do not use pheromone signals when their densities are low and food is plentiful was suspected. An olfactory experiment showed 2,4-dimethyl-3,5-heptanedione was more attractive to $S$. lepidus than the $S$. lineatus and Sitophilus spp. pheromones and, importantly, it elicited positive electrophysiological responses in S. lepidus females. Thus, selecting compounds with similar chemical structure to the known pheromones, but with varying substituent positions, appears a reasonable strategy for isolating the $S$. lepidus aggregation pheromone. 